\title{
A Study to Assess the Musculoskeletal Discomforts Experienced by the Cashiers of Selected Retails Stores of Vadodara City
}

\author{
Shilpi Saraswat and Hridishruti Saikia \\ Department of Family and Community Resource Management, Faculty of Family and Community \\ Sciences, The Maharaja Sayajirao University of Baroda, Vadodara, Gujarat, India \\ Corresponding author email: saraswat.shilpi@gmail.com
}

\section{ABSTRACT}

Retail sector in India is the second largest employer after agriculture. A team of several workers are involved in these retail stores such as cashier, sales associate, store manager, cleaning and maintenance worker, security guard, team leader and floor manager. The present study focuses on the cashiers of the retail stores who perform several roles such as scanning and billing the products purchased by the customers and bagging the products purchased. All these tasks are carried out by them in standing position for 8 to 9 hours a day. They further have to perform repetitive movements of hands and legs while standing. Therefore, the retail store cashier's work has been associated with high rates of musculoskeletal discomforts. The present study was descriptive in nature. Through purposive sampling technique 61 cashiers are selected from nine different retail stores of Vadodara city who were working as a cashier for minimum 12 months. Interview schedule was developed to collect the background information of the cashiers. The standardized questionnaire namely "Nordic Questionnaire" was used to study the discomforts experienced by the cashiers while performing their tasks during last 12 months, last 7 days in different body parts. It also focused on finding out the discomforts that prevented the cashiers in carrying out daily activities during last 12 months. The findings revealed that majority of the respondents experienced discomfort in their lower back, upper back, knees, ankles and feet during last 12 months. It was also found that since last 7 days majority of the respondents experienced discomfort in their upper back (cervical), shoulders and lower back. Further, the respondents reported pain in upper back, lower back, knees, feet and ankles prevented them from carrying out their normal activities during last 12 months. Focusing on these problems some recommendations were suggested to the cashiers to reduce their discomforts.

KEY WORDS: MUSCULOSKELETAL DISCOMFORTS, CASHIERS, RETAIL STORES.

\section{INTRODUCTION}

Retailing in India is one of the pillars of Indian economy (McKinsey, 2007). India is the world's fifth-largest global destination in the retail space. It accounts for over 10 per cent of the country's Gross Domestic Product (GDP) and around 8 per cent of the employment (IBEF, 2019). A team of several workers are involved in these retail stores such as cashier, sales associate, store manager,

Biosc Biotech Res Comm P-ISSN: 0974-6455 E-ISSN: 2321-4007

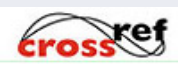

Identifiers and Pagination

Year: 2021 Vol: 14 No (9) Special Issue

Pages: $42-48$

This is an open access article under Creative

DOI: $h t t p: / / d x$.doi.org/10.21786/bbrc/14.9.10
Commons License Attribn 4.0 Intl (CC-BY). cleaning and maintenance worker, security guard, team leader and floor manager (Comentale et.al. 2018). These without these workers the retail stores are can't be alive. Moreover, they play a very important role in buyerseller interactions. To make buyer-seller interactions successful it is important to take care of their workrelated discomforts which may reduce their productivity. It was found through preliminary survey that cashiers at checkout counters were working in standing position throughout their shift.

They were also subjected to repetitive tasks and awkward postures. Therefore, the retail store cashier's work has been associated with high rates of musculoskeletal discomforts. Due to repetitive tasks and awkward postures they may develop neck-shoulder pain, carpal tunnel workers play a very important role in the retail stores,
Article Information

Received: $14^{\text {th }}$ Apr 2021

ccepted after revision: $14^{\text {th }}$ June 2021 
syndrome and back pain (Maligaya et al. 2011) which as a result absenteeism and low productivity increases. Work-related musculoskeletal discomforts bring about a lot of harmful effects. Moreover, people who experience these discomforts suffer mentally and physically and are faced with the possibility of permanent, partial or total disability (Maligaya et al. 2011).Therefore, it becomes imperative to reduce such problems for a productive and safe work environment. The present study highlights the discomforts experienced by the cashiers of retail stores. The results of the study will help the designers of checkout counters of retail stores to consider the discomforts experienced by cashiers while designing them. The outcome of the research will also wrench the attention of the retails store authorities to contemplate the discomforts of their employees considering which can reduce absenteeism and increase productivity.

Statement of Problem: The present study aims to assess the musculoskeletal discomforts experienced by the cashiers of selected retail stores.

Objectives of the study: To assess the musculoskeletal discomforts experienced by the cashiers of selected retail stores.

\section{Hypothesis of the study}

$\mathbf{H}_{1}$ : There exists a relationship between discomforts experienced by the cashiers during last 12 months with age of the respondents.

$\mathbf{H}_{2}$ : There exists a relationship between the discomforts experienced by the cashiers during last 12 months and discomforts that prevented them from carrying out their normal activities during last 12 months.

Review Of Literature: A study was conducted by Forcier et al. (2008) on "Supermarket Workers: Their work and their health, particularly their self-reported musculoskeletal problems and compensable injuries". The musculoskeletal health of supermarket employees other than cashiers was examined for one company. Two sources of data were used compensation statistics (from the company's 57 corporate supermarkets) and self-reported questionnaires (administered in 4 selected stores). The data about the musculoskeletal health of these workers were collected by means of a self-administered questionnaire known as Nordic Questionnaire. The findings of the study revealed that $83 \%$ of workers (excluding cashiers) reported at least one musculoskeletal disorder over a 12- month period, and 32\% had problems severe enough to impede regular activities. An experimental study was conducted by Lehman et.al (2010) on "Effect of sitting versus standing and scanner type on cashiers".

This study was conducted to understand the effects of working position (sitting versus standing) and scanner type (bi-optic versus single window) on muscle activity, upper limb and spinal posture, and subjective preference of cashiers. Ten cashiers from Dutch retailer participated in the study. The findings of the study showed that cashiers exhibited lower muscle activity in the neck and shoulders when standing and using a bi-optic scanner. Shoulder abduction was also less for standing conditions. In addition, all cashiers preferred using the bi- optic scanner with mixed preferences for sitting $(n=6)$ and standing $(n=4)$. A study was conducted by Kihlstedt and Hagg (2011) on "Checkout cashier work and counter designVideo movement analysis, musculoskeletal disorders and customer interaction" in Sweden in order to analyze checkout cashiers' movements at a checkout counter during interaction with customers and the prevalence of work-related stress and musculoskeletal disorders in checkout cashiers. The research was conducted among 50 cashiers from 7 shops. Cashier activities and movements, customer interaction and counter design issues were analyzed from the video data.

Prevalence of work - related stress and musculoskeletal disorders was obtained from the questionnaire. The findings of the study showed that the prevalence of Musculoskeletal Disorders among the cashiers was quite high despite their low average age and the large number of male cashiers. The highest prevalence of MSD was in the neck (68\%), shoulders (66\%), lower (58\%) and upper back (50\%). The results showed that many cashiers experienced stress. The behavior of the customers was the major cause of stress. Other sources of stress arose from bad design or function of the computer system or other technical equipment. Maligaya et al. (2011) conducted a study on "Ergonomic assessment of the working conditions of checkout counter cashiers in a Grocery store" in Phillippines. This study aimed to investigate the working conditions of the cashiers in one of the grocery store in the country. The focused grocery store has five cashiers who were female with age ranging from 21 to 33 years old. The perceived pain of each worker was determined using Cornell Musculoskeletal Discomfort Questionnaire (CMDQ). Rapid Entire Body Assessment (REBA) was conducted to evaluate their postures and identify the level of risk of developing musculoskeletal disorders (MSD). The results of the CMDQ showed that the neck, thighs, and feet are the body regions that ranked the highest in terms of prevalence of musculoskeletal discomfort (five out of five workers).

These were followed by the shoulders, upper and lower back, upper arms, lower legs and hips/buttocks with four workers out five experiencing discomfort. Three workers experienced discomfort in the knees and two in the wrists and forearms. The tasks barcode scanning, reaching and bagging produce higher REBA scores compared to the other tasks such as getting a bag and operating the cash register. This puts them more at risk due to the longer duration of time spent doing the tasks. Capodaglio (2017) conducted a study on "Occupational risk and prolonged standing work in apparel sales assistants". The aim of this study was to assess the postural risk of sales assistants working in a prolonged standing posture, focusing on critical issues for the lower limbs. The study was conducted in 70 sales assistants employed among 9 apparel stores in northern Italy. An observational approach was adopted together with the application of 
standard ergonomic tools (RULA, REBA, Strain Index, OCRA) to assess the postural risk.

The findings of the study indicated that the work of sales assistants in the apparel retail sector was characterized by the prolonged standing posture which accounts for more than $80 \%$ of the work shift duration, alternation with walking phases occur according to assigned tasks and work organization. The musculoskeletal discomfort of the lower limbs reaches a medium- high intensity in 75\% of the workers at the end of the work shift. Comentale et al. (2018) conducted a study on "Comfort and ergonomics evaluation of a checkout workstation" in Italy. This study analyzed how cashiers move themselves into their workspace, with their own tools and devices and do their jobs. Photo and video acquisition has been done to acquire postures and movements by DARTFISH software and DELMIA software was used to model humans postures, workstation and interactions. The results were processed by CaMAN software. The results of the study showed a good correlation among subjective evaluations and calculated comfort indexes. In particular, high correlations have been found for neck, shoulders and hand.

\section{METHODOLOGY}

Descriptive design was thought to be most appropriate method to carry out the present research. The locale of the study was Vadodara city. The sample for the present study was collected from nine different retail stores of Vadodara city. The data were collected from 61 respondents who were working as a cashier for minimum 12 months in the selected retail stores of Vadodara city. Therefore, purposive sampling technique was used for the selection of respondents from the retail stores. Interview schedule was developed to collect the background information of the cashiers. The standardized questionnaire namely "Nordic Questionnaire" was used to study the discomforts experienced by the cashiers while performing their tasks during last 12 months, last 7 days in different body parts viz. neck, shoulder, upper back, upper arm, lower back, forearm, wrist, hip, thigh, knee, ankles and feet. It also focused on finding out the discomforts that prevented the cashiers in carrying out daily activities during last 12 months in different body parts viz. neck, shoulder, upper back, upper arm, lower back, forearm, wrist, hip, thigh, knee, ankles and feet.

Major Findings: The findings of the study obtained through the analysis of the data supported discussion and interpretations are presented here.

Section 1 Background information: This section contained questions regarding the personal information of the respondents covering details on their age (in years), Gender, height (in cms), weight (in kg), marital status, years of service as cashiers, number of days at work in a week, total working hours per day, number of break in a day, duration of each breaks in a day. It was found that all the respondents of selected retail stores had 6 working days in a week and their working hours were 9 hours per day. The data in Fig.2 depicted that majority $(81.96 \%)$ of the respondents had 1 to 2 breaks in a day and 18.03 per cent of the respondents had 3 to 4 breaks in a day. The duration of tea/coffee breaks in a day was 15 minutes and lunch breaks was 30 to 60 minutes in a day at selected retail stores. Majority (81.96\%) of the respondents had one tea/coffee break in a day and 18.03 per cent of the respondents had two tea/coffee breaks in a day. It was also found that less than three - fourth $(70.49 \%)$ of the respondents had one lunch break of 60 minutes in a day while and more than one - fourth $(29.50 \%)$ of the respondents had one lunch break of 30 minutes in a day. From Fig. 3, it was found that all of the respondents reported that they did not had any musculoskeletal problems before joining as cashier at the present retail stores.

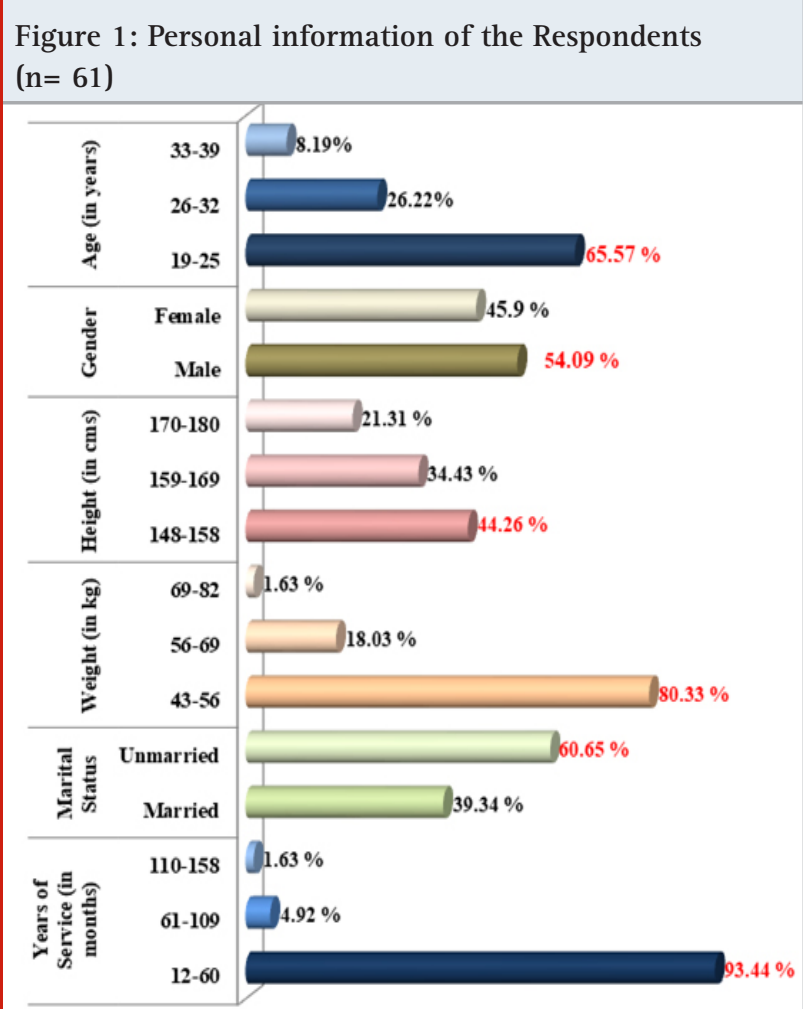

Figure 2: Work related information of the respondents $(\mathrm{n}=61)$

\begin{tabular}{|c|c|c|}
\hline \multirow{2}{*}{ 党 } & $3-4$ & $18.03 \%$ \\
\hline & $1-2$ & $81.96 \%$ \\
\hline \multirow{4}{*}{ 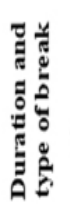 } & One 60mins lunch break & $70.49 \%$ \\
\hline & One 30mins lunch break & $29.5 \%$ \\
\hline & Two 15mins tea/coffee breaks & $18.03 \%$ \\
\hline & & $81.96 \%$ \\
\hline
\end{tabular}

Section 2 (Discomfort experienced by the cashiers): In this section, a standardized questionnaire namely "Nordic Questionnaire" was used to study the discomforts experienced by the cashiers while performing their 
tasks during last 12 months, last 7 days in different body parts viz. neck, shoulder, upper back, upper arm, lower back, forearm, wrist, hip, thigh, knee, ankles and feet. It also focused on finding out the discomforts that prevented the cashiers in carrying out daily activities during last 12 months in different body parts viz. neck, shoulder, upper back, upper arm, lower back, forearm, wrist, hip, thigh, knee, ankles and feet. The data in Fig. 4 , revealed that majority (88.52\%) of the respondents experienced discomfort in their upper back (cervical) during last 12 months. Less than three-fourth (70.49\%) of the respondents had encountered discomfort in their right wrist during last 12 months. It was also found that less than two - third (62.29\%) of the respondents had discomfort in both shoulder during last 12 month.

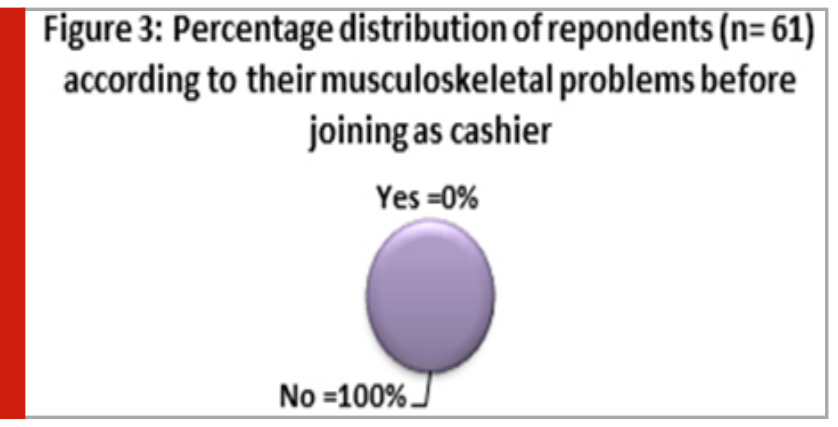

Figure 4: Discomforts experienced in upper body parts during last 12 months

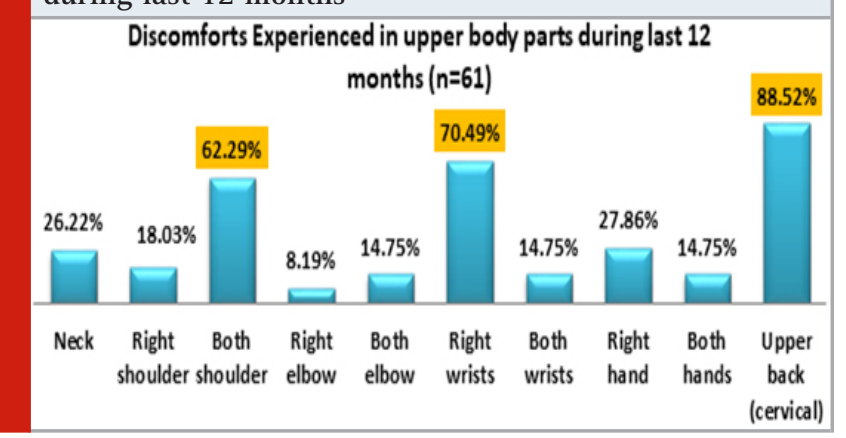

Figure 5: Discomforts experienced in upper body parts during last 7 days

Discomforts experienced in upper body parts during last 7 days ( $n=61$ )

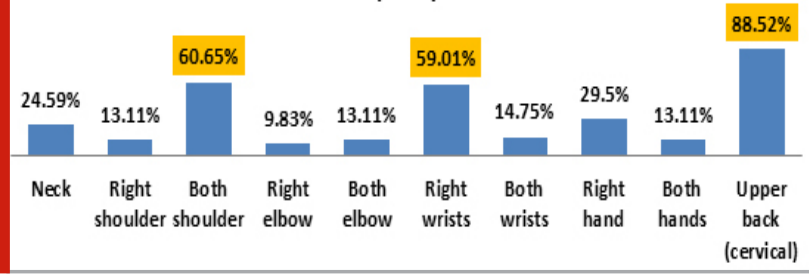

From the Fig. 5, it was found that since last 7 days, majority $(88.52 \%)$ of the respondents experienced discomfort in their upper back (cervical). Less than two - third (60.65\%) of the respondents experienced discomfort in their both shoulder. Moreover, 13.11 per cent of the respondents experienced discomfort in their right shoulder. More than one - half (59.01\%) of the respondents experienced discomfort in their right wrist and 14.75 per cent of the respondents experienced discomfort in both the wrist. Fig. 6 revealed that majority (98.36\%) of the respondents had experienced discomfort in their lower back (lumber) during last 12 months. More than three-fourth (78.68\%) of the respondent had discomforts in their both knees during last 12 months. It was also found that less than three - fourth (73.77\%) of the respondents experienced discomforts in their ankles and feet during last 12 months.

Figure 6: Discomforts experienced in lower body parts during last 12 months

Discomforts experienced in lower body parts during last 12 months (n=61)

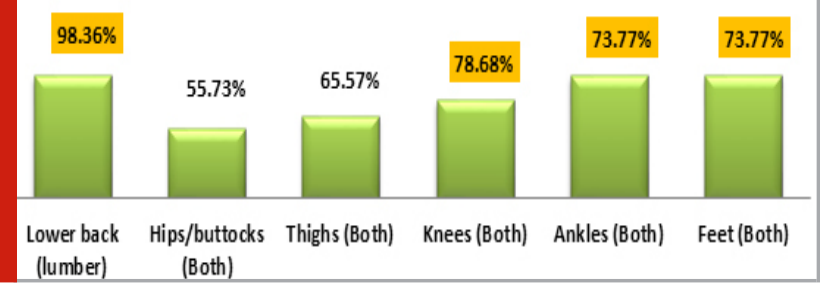

Figure 7: Discomforts experienced in lower body parts during last 7 days

Discomforts experienced in lower body parts during 7 days $(n=61)$

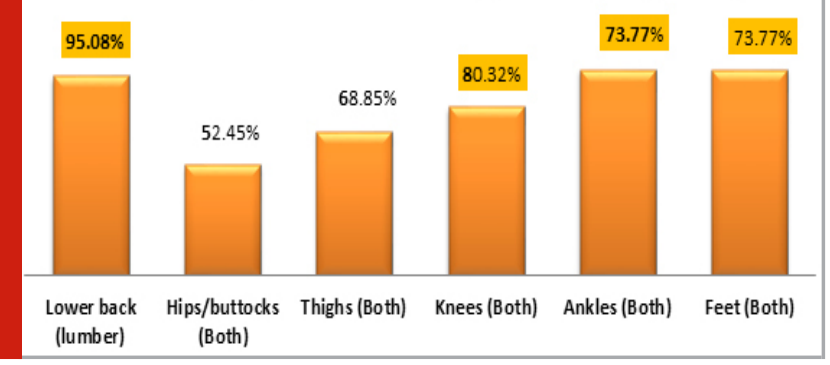

Figure 8: Discomforts in upper body parts that prevented the cashiers from carrying out their normal activities during last 12 months

Discomforts in upper body parts that prevented the cashiers from carrying out their normal activities during last 12 months $(n=61)$

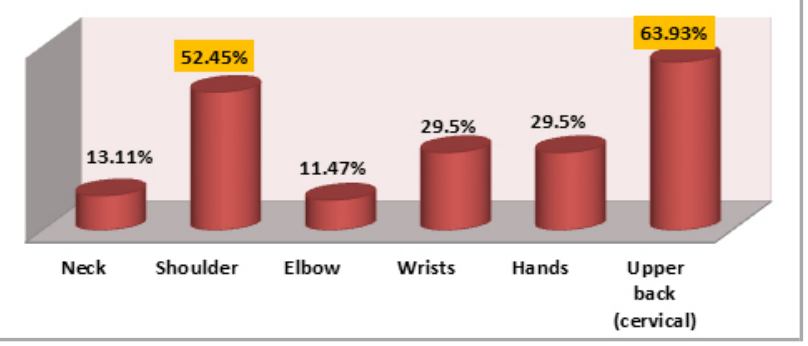

The data in Fig. 7 depicted that in lower body parts, majority (95.08\%) of the respondents experienced discomfort in their lower back and knees (80.32\%) during last 7 days. Less than three fourth (73.77\%) of the respondents experienced discomfort in their ankles and feet during last 7 days. It was revealed that less than two - third (63.93\%) of the respondents experienced discomfort in their upper back during last 
12 months which prevented them from carrying out their normal activities. More than one - half (52.45\%) of the respondents experienced discomforts in their shoulder during 12 months which prevented them from carrying out their normal activities viz. household activities and other jobs (Fig. 8).

Due to discomforts experienced in lower back (lumber) three-fourth (75.4\%) of the respondents were prevented from carrying out their normal activities during last 12 months (Plate 10). It was also revealed that less than three - fourth (70.49\%) of the respondents experienced discomforts in knees and two - third (63.93\%) of the respondents experienced discomfort in their ankles during last 12 months which prevented them from carrying out their normal activities (Fig. 9).

Figure 9: Discomforts in lower body parts that prevented the cashiers from carrying out their normal activities during last 12 months

Discomforts in lower body parts that prevented the cashiers from carrying out their normal activities during last 12 months $(n=61)$

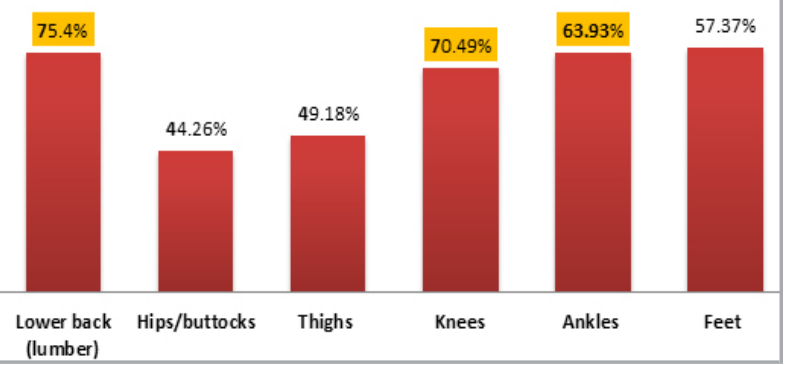

Testing of Hypotheses: Several hypotheses were formulated to find out the relationship between selected variables of the present study. In the present investigation, as per the nature of variables t-test, coefficient of correlation and Analysis of the Variance (ANOVA) were computed. For the purpose of statistical analysis, the hypotheses were formulated in null form. The results are presented in this section:

$\mathbf{H O}_{\mathbf{1}}$ : There exists no variation in the discomforts experienced by the cashiers during last 12 month and Age (in years) of the respondents: Analysis of Variance (ANOVA) was computed to test the hypothesis.

The computation of F - value showed significant variation in the discomforts experienced by the cashiers with age (in years) of the respondents. The $\mathrm{F}$ - value was not found significant for years of service as cashier (in months) (Table 1). Hence, the null hypothesis was partially accepted. Thus, it was inferred that the discomforts experienced by the cashiers varied with their age (in years).

$\mathrm{Ho}_{2}$ : There exists no relationship between the discomforts experienced by the cashiers during last 12 months and discomforts that prevented them from carrying out their normal activities during last 12 months: Co-efficient of correlation was computed to find out relationship between the discomforts experienced by the cashiers during last 12 months and discomforts that prevented them from carrying out their normal activities during last 12 months.

Table 1. Analysis of Variance showing variation in the discomforts experienced by the cashiers with selected personal variables viz. Age (in years) and Years of service as cashiers (in months)

\begin{tabular}{|c|c|c|c|c|c|c|}
\hline Sr. No. & $\begin{array}{l}\text { Selected } \\
\text { Variables }\end{array}$ & df & $\begin{array}{l}\text { Sum of } \\
\text { Squares }\end{array}$ & $\begin{array}{c}\text { Mean } \\
\text { Squares }\end{array}$ & F-value & $\begin{array}{c}\text { Level of } \\
\text { Significance }\end{array}$ \\
\hline 1. & & & \multicolumn{2}{|c|}{ Age (in years) } & & \\
\hline & Between Groups & 2 & 154.533 & 77.267 & 5.474 & 0.01 \\
\hline & Within Groups & 58 & 818.713 & 14.116 & & \\
\hline
\end{tabular}

Table 2. Co-efficient of correlation showing relationship between the discomforts experienced by the cashiers during last 12 months and discomforts that prevented them from carrying out their normal activities during last 12 months

\begin{tabular}{|l|c|c|c|}
\hline Selected Variables & $\mathrm{n}$ & r-value & Level of significance \\
\hline $\begin{array}{l}\text { Discomforts experienced } \\
\text { by the cashiers during last 12 months }\end{array}$ & & & \\
\hline $\begin{array}{l}\text { Discomforts that prevented them from } \\
\text { carrying out their normal activities } \\
\text { during last } 12 \text { months }\end{array}$ & 61 & 0.764 & 0.01 \\
\hline
\end{tabular}


The results revealed that their existed significant relationship between the discomforts experienced by the cashiers during last 12 months and discomforts that prevented them from carrying out their normal activities during last 12 months. Hence, the null hypothesis was rejected (Table 2). It can be concluded that more is the discomforts experienced by the cashiers during last 12 months more was they were prevented them from carrying out their normal activities during last 12 months.

Figure 10: Best and preferred work zone

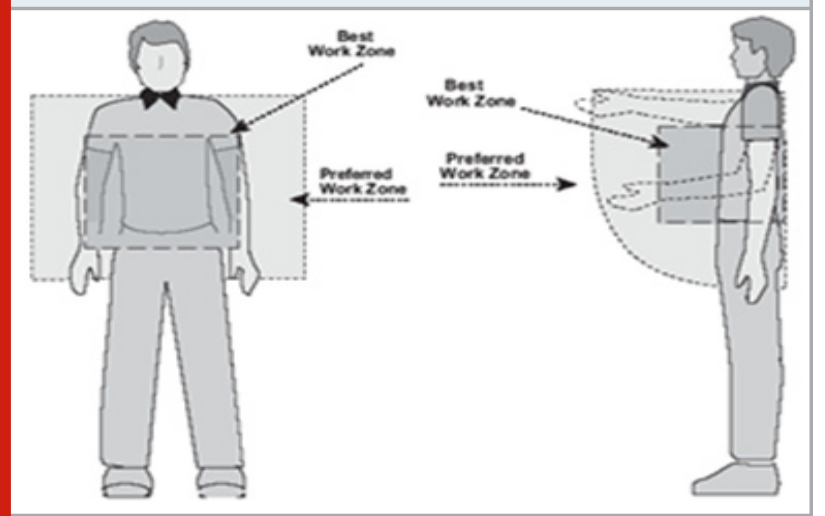

Figure 11: Cashier working at Best work zone

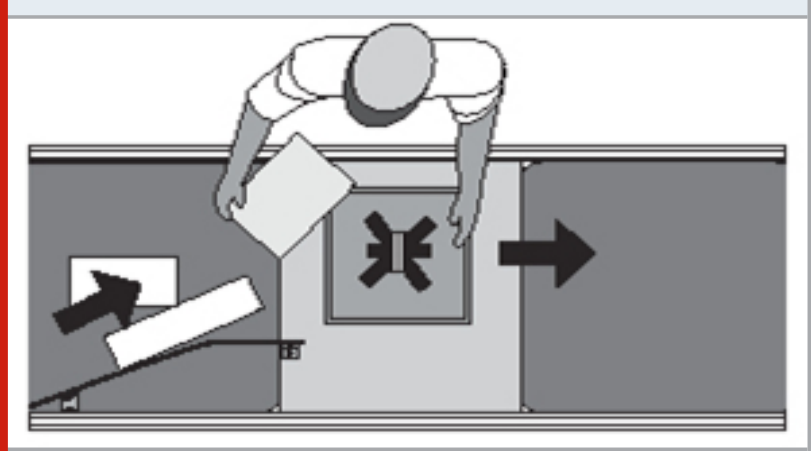

Figure 12: Cashier working at preferred work zone

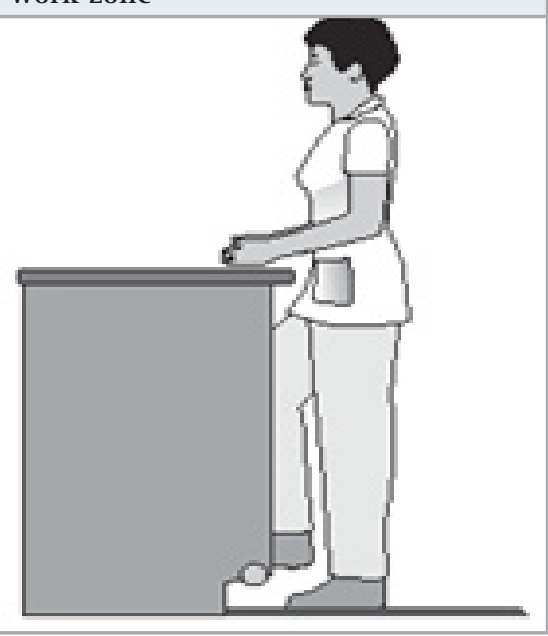

Figure 13: Cashier using keyboard to enter items

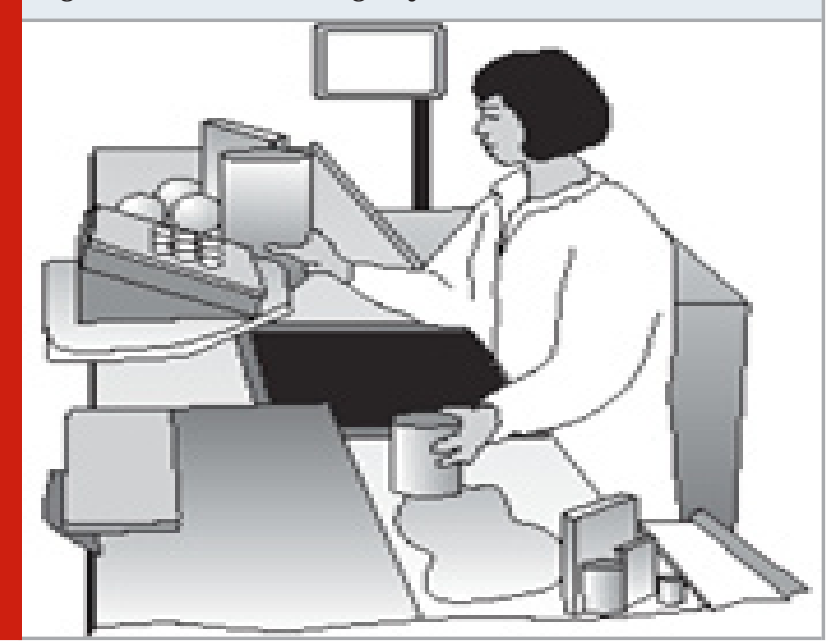

Figure 14: Sliding items across the scanner

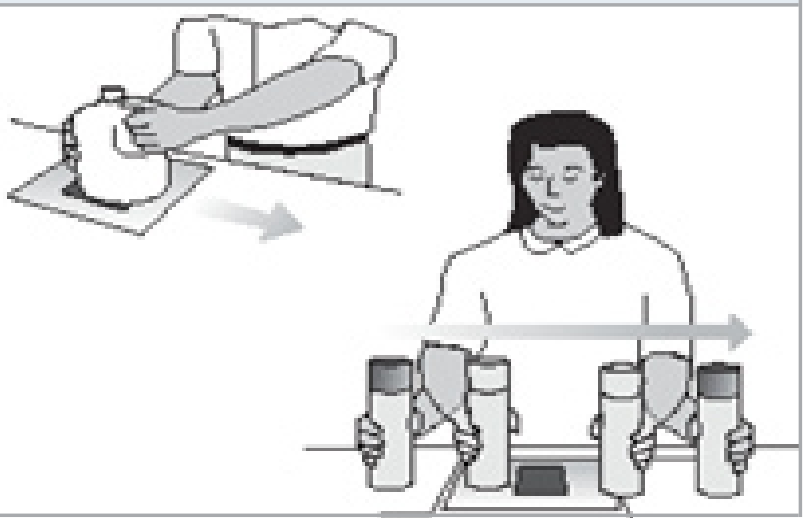

\section{CONCLUSION AND RECOMMENDATION}

From the present study it was found that the cashiers experienced some musculoskeletal discomforts while working. These discomforts lead them to some musculoskeletal disorders such as back injuries, muscle strain, carpal tunnel syndrome, rotator cuff injuries (a shoulder problem) and many more if continued further. Therefore, there is a need to suggest ergonomic tips for reducing discomforts and the environmental parameters which will help them to increase their productivity and reduces absenteeism. Occupational Safety and Health Administration (OSHA) (2004) provided practical recommendations to help retail store cashiers to reduce the musculoskeletal discomforts in their workplaces. This can be done by recommending correct working postures.

1. Recommended Working Postures: According to Occupational Safety and Health Administration (OSHA), recommended Working Postures describe body positions that are neutral and comfortable to use. Using postures other than those recommended will generally waste energy and motion as well as potentially raise the risk of injury. Changing position frequently and stretch between tasks helps 
in improving circulation and lessens fatigue.

2. Best and Preferred Work Zone: Performing work within the best and preferred work zones facilitates productivity and comfort. Work is safest when lifting and reaching is performed in these zones. Working outside these work zones results in non-neutral postures that may increase the risk of injury. It is particularly important to perform heavy lifting tasks within the best work zone (Fig. 10).

3. Checkout and Bagging: Checking out and bagging were the regular tasks of the cashiers. They have to perform these tasks for every customers visited to the retail stores. Thus, they were subjected to awkward postures and repetitive which as a result developed musculoskeletal discomforts among the cashiers. Given below are some ergonomic tips given by Occupational Safety and Health Administration (2004) to cope with these problems.

- A powered in-feed conveyor should be used to help cashiers bring the items to their best work zone, rather than leaning and reaching to get items further up the conveyor (Fig. 11).

- In-feed and take-away conveyor belts should be placed as close as possible to the cashier to minimize reaching.

- Work should be performed within the preferred work zone (Fig. 12).

- Keyboards should be considered to enter the quantity of identical products rather than scanning each individual item (Fig. 13).

- Keyboards should be used to enter code if item fails to scan after second attempt.

- Keyboards should be placed on supports that adjust in height, horizontal distance and tilt to keep work within the preferred work zone.

- Cash register displays should be placed at or slightly below eye level.

- Scan cards or scan guns should be used for large or bulky items to eliminate the need to handle them.

- Scanners and conveyors should be set at the same height so that cashiers can slide items across rather than lift them (Fig. 14).

Cashiers should wear suitable and supportive shoes. The shoes shall be able to maintain the shape of the foot and provide support for the arch of the foot; have adequate space to allow movement of toes; have shock-absorbing insoles, and have low heels (not higher that $5 \mathrm{~cm}$ or 2 inches). Suitable shoes can reduce the health risks of standing. Standing on anti-fatigue mats, as compared to bare floors, provides a noticeable improvement in comfort. It reduces back pain and stress when standing for long period of time, prevents from injury and fatigue and also reduces foot pressure. When cashiers works by standing for longer period of time, certain body parts are going to become stiff such joints, especially knees are the most at risk of experiencing this minor annoyance which can lead to major. The anti-fatigue mat prevents from such stiffness. It also promotes good postures. The rubbery and cushioned surface will keep the cashier balanced and relaxed even when they are not moving. This way, the blood flow of the body is not disrupted, promoting good posture in the process. Anti-fatigue mat also eliminate fatigue while working for long hours. This leads to a substantial reduction of stress. (CCOHS, 2015). The cashiers should encourage to perform appropriate stretching exercises to relax their legs during work breaks.

\section{REFERENCES}

Anti-Fatigue mats (2015). Canadian center for Occupational Health and Safety (2015). Retrieved from https://www.ccohs.ca/oshanswers/ergonomics/mats. html

Capodaglio Edda Maria (2017). Occupational risk and prolonged standing work in apparel sales assistants. International Journal of Industrial Ergonomics. Retrieved from http://dx.doi.org/10.1016/j.ergon.2016.11.010 on 2nd October, 2019.

Comentale M., Naddeo F., Contrada A., Forlone G., and Saturno G., (2018). Comfort and ergonomics evaluation of a checkout workstation. ARPN Journal of Engineering and Applied Sciences. Vol.13,No.13, July 2018. Retrieved from www.arpnjournals.com on 8th July, 2019.

Forcier L., Lapointe C., Lortie M., Buckle P., Kuorinka I., Lemaire J., and Beaugrand S. (2008). Supermarket workers: Their work and their health, particularly their self-reported musculoskeletal problems and compensable injuries. Retrieved from https://www. researchgate.net/publication/23192489 on 8th July, 2019.

Kihlstedt A. and Hagg G. M. (2011). Checkout cashier work and counter design- Video movement analysis, musculoskeletal disorders and customer interaction. International Journal of Industrial Ergonomics. February 2011. Retrieved from www.elsevier.com/locate/ ergon on 8th July, 2019.

Lehman K. R., Psihogios J. P. and Meulenbroek R. G. J. (2010). Effects of sitting versus standing and scanner type on cashiers. Retrieved from https://www. tandfonline.com/loi/terg20 . on 10th July, 2019.

Maligaya V. H. V., Sanchez M. M. P., Andreana C., Portus A. J. A. (2011). Ergonomic Assessment of the working conditions of checkout counter cashiers in a grocery store in the Philippines. Retrieved from https://www. jstage.jst.go.jp/article/jje/53/Supplement2/53_S612/_ pdf/-char/ja on 9th July, 2019.

McKinsey (2007). The Bird of Gold- The Rise of India's Consumer Market. Retrieved from https:// en.m.wikipedia.org/wiki/Retailing_in_India on 23rd July, 2019.

Occupational Safety and Health Administration (2004). Ergonomics for the prevention of Musculoskeletal Disorders. U.S. Department of Labor Occupational Safety and Health Administration OSHA 3192-06N.

Occupational Safety and Health Branch Labour Department (2018). Guidance Notes on Standing at work and service counter Design, published by Labour Department. Retrieved from http://www.labour.gov.hk on 15th January 2020.

Retail Industry in India (2019). India Brand Equity Foundation (IBEF). Retrieved from https://www.ibef. org/industry/retail-india.aspx on 11th March, 2020. 